\title{
Relato de experiência na implantação de hortas escolares na educação básica e superior
}

Fabiana Rodrigues da Silva ${ }^{1}$, Airton Rodrigues dos Santos ${ }^{2}$, Vanessa Cláudia Vasconcelos Segundo ${ }^{3}$, Eveline Nogueira Lima ${ }^{4}$

\section{Resumo}

Uma horta constitui uma área, geralmente de pequena extensão, onde pode ser realizada a atividade de cultivo das mais diversas culturas agrícolas, como legumes ou hortaliças, submetidas a um manejo intensivo de produção. O objetivo deste trabalho foi avaliar a implantação e o desenvolvimento de hortas orgânicas em distintos usos didáticos, frente a diferentes níveis de ensino: educação básica e educação superior. Em ambos os locais de implantação das hortas foi realizada a aplicação de questionários e após tabulação desses dados foi possível concluir que, na educação básica, a horta teve como efeito a sensibilização e a educação ambiental. Já para a educação superior serviu como treinamento técnico profissional para os futuros agroecólogos em formação. Portanto, a implantação de hortas é uma metodologia ativa de ensino que pode ser usada em diferentes níveis de ensino e com diferentes objetivos.

\section{Palavras-chave}

Educação Profissional. Educação Ambiental. Implantação. Ferramenta didática. Agroecologia.

\footnotetext{
${ }^{1}$ Doutoranda em Fitotecnia na Universidade Federal Rural do Semi-Árido, Rio Grande do Norte, Brasil. E-mail: agro.fabirodrigues@gmail.com.

${ }^{2}$ Especialista em Gestão Ambiental no Instituto Federal de Educação, Ciência e Tecnologia do Rio Grande do Norte, Campus Natal Central, Brasil; chefe de Departamento do Meio Ambiente da Prefeitura Municipal de Itajá, Rio Grande do Norte, Brasil. E-mail: airtonrodriguestcc@gmail.com.

3 Doutora em Agronomia (Fitotecnia) pela Universidade Federal do Ceará, Brasil. E-mail: vanessac_vasconcelos@yahoo.com.br.

4 Doutora em Agronomia (Fitotecnia) pela Universidade Federal do Ceará, Brasil. E-mail: evelinenlima@gmail.com.
} 


\title{
Experience report in the implementation of school gardens in elementary and higher education
}

Fabiana Rodrigues da Silva ${ }^{5}$, Airton Rodrigues dos Santos ${ }^{6}$, Vanessa Cláudia Vasconcelos Segundo Eveline Nogueira Lima ${ }^{8}$

\begin{abstract}
A vegetable garden is an area, usually of small extension, where the cultivation of the most diverse agricultural crops can be carried out, such as legume, submitted to intensive production management. The objective of this work was to evaluate the implantation and development of organic gardens in different didactic uses, considering different levels of education: basic education and higher education. Questionnaires were applied in both places of implementation of the gardens, and after tabulating these data, it was possible to conclude that in basic education, the garden had the effect of raising awareness of environmental education. As for higher education, it served as professional technical training for future agroecologists in training. Therefore, the establishment of gardens is an active teaching methodology that can be used at different levels of education and with different objectives.
\end{abstract}

\section{Keywords}

Professional Education. Environmental Education. Implantation. Didactic tool. Agroecology.

\footnotetext{
${ }^{5} \mathrm{PhD}$ student in Plant Science, Federal Rural University of the Semi-Arid, State of Rio Grande do Norte, Brazil. E-mail: agro.fabirodrigues@gmail.com.

${ }^{6}$ Specialist in Environmental Management, Federal Institute of Education, Science and Technology of Rio Grande do Norte, Campus Natal Central, State of Rio Grande do Norte, Brazil; head of the Department of the Environment at the Municipality of Itajá, State of Rio Grande do Norte, Brazil. E-mail: airtonrodriguestcc@gmail.com.

$7 \mathrm{PhD}$ in Agronomy (Phytotechnics), Federal University of Ceará, State of Ceará, Brazil. E-mail: vanessac_vasconcelos@yahoo.com.br.

$8 \mathrm{PhD}$ in Agronomy (Phytotechnics), Federal University of Ceará, State of Ceará, Brazil. E-mail: evelinenlima@gmail.com.
} 


\section{Introdução}

As preocupações em relação à alimentação vêm se modificando com o passar do tempo (MARTINELLI; CAVALLI, 2019) e, consequentemente, a busca por uma alimentação livre de insumos químicos e mais saudável vem se tornando frequente.

Saber da procedência do alimento adquirido nas prateleiras do supermercado ou até mesmo na barraca da feira é necessário para a certificação daquilo que está indo à mesa. Em busca da autossuficiência de alimentos livres de insumos químicos, está aumentando o número de pessoas que buscam produzir o seu próprio alimento de maneira natural, barata e em pequenos espaços.

Portanto, hoje em dia, produzir seu próprio alimento em pequenas hortas e pomares voltou a ser uma atividade importante, tanto do ponto de vista nutricional e alimentar quanto em relação à qualidade de vida, por ser uma atividade física e lúdica (SIMONETTI; LOPES; OLIVEIRA, 2017).

Aquele que cultiva seus próprios alimentos de forma adequada não precisa preocuparse com assuntos complexos, como contaminação microbiológica ou por agrotóxicos, e nem com produtos de origem transgênica, entre outros, porque produz suas próprias hortaliças de forma saudável e isenta de resíduos (SIMONETTI; LOPES; OLIVEIRA, 2017).

As hortas, atualmente, ultrapassaram as fronteiras dos quintais das casas e passaram a ser parte também das atividades escolares (CYPRIANO et al., 2018). De acordo com Silva e Scalabrin (2020), a criação da horta na escola representa uma estratégia de aproximação da relação teoria e prática e da ação docente interdisciplinar, de modo a ressignificar o ensino e possibilitar o envolvimento dos estudantes, na medida em que os conhecimentos desenvolvidos na escola partem da realidade local.

A horta escolar na educação básica é um importante instrumento para o aprendizado e para a cidadania. As crianças não nascem com essas habilidades, que precisam ser assimiladas e exercitadas (LEITE, 2020). Na educação superior, os profissionais da área de ciências agrárias, agroecólogos, agrônomos, técnicos agrícolas, técnicos em agroindústria, técnicos em agroecologia, entre outros, são agentes responsáveis pelo acompanhamento técnico e produtivo das hortas, e colocam em prática as técnicas vistas na Academia, como a escolha do local, montagem dos canteiros, métodos de irrigação, adubação, etc., ou seja, um acompanhamento desde o momento de plantio ao momento de colheita dos cultivares produzidos na horta. 
É de fundamental importância o planejamento e o uso de técnicas adequadas em qualquer atividade agropecuária, visando minimizar possíveis impactos ambientais negativos e maximizar os possíveis resultados positivos. A implantação de hortas urbanas, assim como outras realizações, deve ser pensada, desejada e planejada. (LIZ, 2008; MAURICIO, 2020).

Portanto, a horta é um instrumento que pode ter várias finalidades, podendo ser citadas a produção comercial; a produção para suprir as necessidades de uma família ou até mesmo uma comunidade; pode ser usada como meio pedagógico no ensino multidisciplinar, como instrumento de trabalho de profissionais da área agrícola, como trabalhar a conscientização ambiental, a soberania alimentar e recreativa. A prática da implantação de uma horta escolar pode proporcionar várias atividades didáticas, oferecendo diversas vantagens para a comunidade escolar (ENO; LUNA; LIMA, 2015).

Diante do exposto, o objetivo deste trabalho foi avaliar a implantação e o desenvolvimento de hortas orgânicas em distintos usos didáticos, frente a diferentes níveis de ensino: educação básica e educação superior.

\section{Metodologia}

\section{Instituto Federal do Rio Grande do Norte (IFRN)}

O experimento foi realizado no Instituto Federal do Rio Grande do Norte (IFRN), no campus Ipanguaçu, que está situado às margens da RN 118, no Distrito denominado Base Física de Ipanguaçu, contendo uma área que abrange cerca de $1.333 .000 \mathrm{~m}^{2}$ (133 ha).

\section{Construção da horta com os estudantes da educação superior}

Durante o semestre, os alunos participaram de práticas, como o levantamento de canteiros e procedimentos da pesquisa. Foram 17 alunos envolvidos no projeto, divididos em 4 grupos e cada grupo era composto por quatro ou cinco estudantes. Cada grupo ficou responsável por preparar um canteiro e realizar o cultivo das olerícolas em uma área reservada para a turma (Figura 1).

Os canteiros continham no mínimo duas espécies de plantas olerícolas distintas, para cada grupo. O próprio campus, por via dos serviços ofertados pelo setor da fazenda escola, realizou o preparo da área de cultivo, como a limpeza e corte da terra. Este trabalho foi realizado com o maquinário e a mão de obra de terceirizados lotados neste setor. 
Figura 1 - Localização do campus do IFRN, campus Ipanguaçu

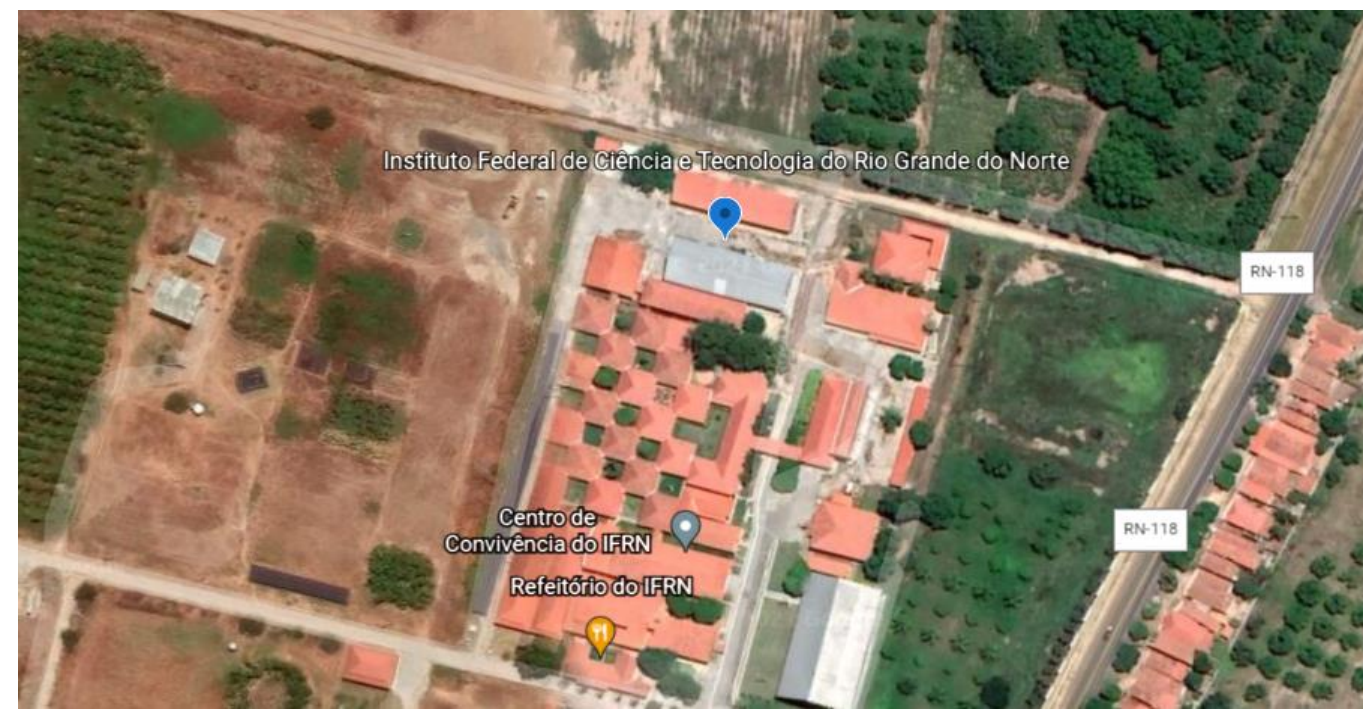

Fonte: Google Earth (2021).

Em seguida foi realizada a escolha dos locais dos canteiros de cada grupo em uma área com cerca de $252 \mathrm{~m}^{2}$, no local de Latitude UTM: 735735 m E e Longitude UTM: $9387715.20 \mathrm{~m} \mathrm{~S}$; cada grupo ficou com um canteiro que media 1 metro de largura por 10 metros de comprimento.

Ao final do projeto, os grupos elaboraram relatórios, contendo toda a metodologia utilizada. Esses trabalhos foram intitulados conforme o exposto no Quadro 1.

Quadro 1 - Divisão dos grupos da educação superior - IFRN, campus Ipanguaçu

\begin{tabular}{|l|l|}
\hline \multicolumn{1}{|c|}{ Grupos } & \multicolumn{1}{c|}{ Temas } \\
\hline 1 & $\begin{array}{l}\text { Germinação de sementes de coentro (coriandrum sativum } l .) \text { e } \\
\text { pimentão (capsicum annuum) sob diferentes dosagens de esterco } \\
\text { bovino. }\end{array}$ \\
\hline 2 & $\begin{array}{l}\text { Análise da produtividade da beterraba (beta vulgaris } l \text { var. } \\
\text { katarina) em diferentes tipos de espaçamentos. }\end{array}$ \\
\hline 3 & $\begin{array}{l}\text { Desempenho da cenoura e da alface sob aplicação de diferentes } \\
\text { adubos verdes orgânicos e fertirrigação. }\end{array}$ \\
\hline 4 & $\begin{array}{l}\text { Desempenho da rúcula e couve manteiga em diferentes adubos } \\
\text { orgânicos. }\end{array}$ \\
\hline
\end{tabular}

Fonte: Os autores (2021). 
O questionário (Quadro 2) e o termo de consentimento para a realização da pesquisa foram aplicados na turma de Tecnologia em Agroecologia. A turma estava no $5^{\circ}$ período de curso, cursando as seguintes disciplinas: Agricultura I, Agricultura II, Avicultura e Suinocultura de Base Ecológica, Piscicultura Ecológica, Sociologia Rural e Olericultura e Plantas Medicinais.

Quadro 2 - Questionário aplicado na educação superior do IFRN, campus Ipanguaçu

\begin{tabular}{|l|}
\hline \multicolumn{1}{|c|}{ Questionário } \\
\hline 1) Você é filho de agricultor / produtor rural? \\
\hline 2) Existe algum cultivo agrícola em sua residência? \\
\hline 3) Você mora na zona rural? \\
\hline 4) Você já tinha tido a experiência de implantar uma horta? \\
\hline 5) Considera que a implantação da horta ajudou você no processo de aprendizado? \\
\hline 6) Você sentiu dificuldade em trabalhar em grupo? \\
\hline 7) Você indicaria a implantação de hortas como prática nas turmas posteriores? \\
\hline 8) Daqui alguns dias, você como Tecnólogo em Agroecologia terá segurança em utilizar os \\
conhecimentos adquiridos na implantação da horta?
\end{tabular}

Fonte: Os autores (2021).

Cada grupo, além de realizar o cultivo, fez uma investigação científica. Para isso, cada grupo preparou um pré-projeto, contendo introdução, justificativa, metodologia, resultados esperados, croqui, e o apresentou em forma de seminário.

Para o cultivo dos canteiros, a turma foi ao campo semanalmente. Findando o projeto, os grupos produziram artigos científicos abordando os experimentos realizados nos canteiros e os apresentaram na forma de seminário. Após o término das apresentações, o questionário semiestruturado foi aplicado de forma surpresa como forma de feedback; todos os alunos foram receptivos ao preenchimento. Após a aplicação dos questionários, os dados coletados foram tabulados em Excel e foram geradas as respectivas porcentagens das respostas. 


\section{Escola Municipal Vereador João Medeiros Lopes, Itajá-RN}

A escola está localizada no Conjunto Habitacional Francisco Euzébio de Figueiredo, na cidade de Itajá-RN, localizada a $205,7 \mathrm{~km}$ da capital Natal - RN.

\section{Implantação da horta na Escola Municipal Vereador João Medeiros Lopes, Itajá-RN}

Após a aprovação e apoio do corpo de servidores da escola, foi dado início às ações necessárias para implantação e manejo da horta e culturas.

O solo e o adubo foram adquiridos a partir de doação de criadores de ovinos, caprinos e bovinos da Comunidade Sítio Caraú, zona rural do município de Itajá. As ferramentas foram adquiridas através da parceria entre a Secretaria Municipal de Agricultura, Pesca e Meio Ambiente e o Projeto Cidade Limpa. A partir desses recursos, os canteiros foram estruturados (Figura 2).

Figura 2 - Localização da Escola Municipal Vereador João Medeiros Lopes, Itajá-RN

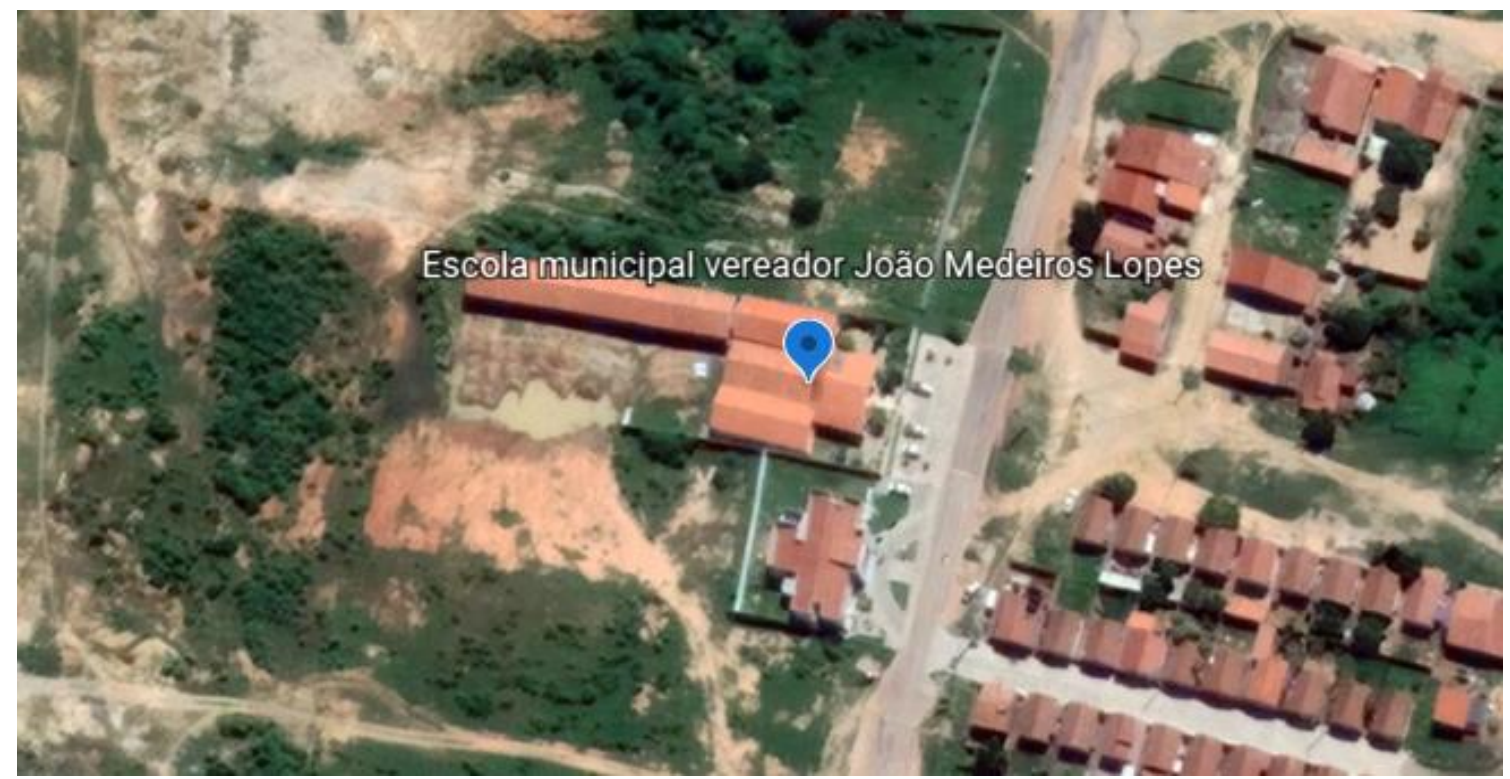

Fonte: Google Earth (2021).

Em dezembro de 2017 foi realizado o primeiro contato das crianças com o espaço onde foi realizado o plantio das hortaliças. Nesse encontro, contamos com a ajuda de professores, diretora, porteiro e coordenadores da escola.

As culturas plantadas foram: coentro (Coriandrum sativum), cebolinha (Allium fistulosum) e cenoura ( $\underline{\text { Daucus carota) }}$, como também plantas medicinais em um outro local, 
com o objetivo de produção de chás naturais. Essas plantas eram: hortelã (Mentha spicata), boldo (Peumus boldus). O acompanhamento dos canteiros foi realizado diariamente pelo porteiro da escola, que já tinha experiência com hortaliças. Por se tratar de uma horta não voltada para a produção, a colheita era realizada em pouca quantidade pelas funcionárias responsáveis pela preparação da merenda escolar e até mesmo as mães quando iam buscar seus filhos.

\section{Aplicação do questionário aos estudantes da educação básica}

Visando adequar-se à realidade escolar das crianças foi feita a aplicação de questionário não estruturado, visto que as crianças cursavam a educação infantil, mais precisamente o $2^{\circ}$ ano, portanto, iniciando a fase de alfabetização. O questionário não estruturado continha 7 (sete) perguntas (Quadro 3) e foi aplicado em março de 2018 na própria escola.

Tabela 3 - Questionário aplicado na educação básica da Escola Municipal Vereador João Medeiros Lopes, Itajá-RN

\begin{tabular}{|l|}
\hline \multicolumn{1}{|c|}{ Questionário } \\
\hline 1) Na sua casa/família existe alguma cultura (planta)? \\
\hline 2) Você já tinha plantado alguma vez? \\
\hline 3) Você gostou da horta na escola? \\
\hline 4) Você conhece alguma escola que tenha o projeto de horta na escola? \\
\hline 5) O que você aprendeu/achou mais legal com a horta? \\
\hline 6) Qual a hortaliça (planta) você gostaria que tivesse na horta da escola? \\
\hline 7) Qual a hortaliça que você mais gosta de comer? \\
\hline
\end{tabular}

Fonte: Os autores (2021).

Para que as crianças ficassem mais à vontade para responder ao questionário, foi feito um semicírculo, em que se fez uma acolhida bem descontraída e as perguntas foram feitas em forma de entrevista. Vale ressaltar que a devida permissão para a aplicação desse questionário foi realizada junto aos pais, diretora da escola e a professora da turma.

As crianças foram receptivas, demonstraram entusiasmo e não hesitaram durante o momento da entrevista. Após a aplicação dos questionários, os dados coletados foram tabulados em Excel, e geradas as respectivas porcentagens das respostas. 


\section{Resultados e Discussão}

Resultados do questionário aplicado na educação superior - Curso de Agroecologia IFRN, campus Ipanguaçu

$\mathrm{Na}$ avaliação do perfil dos estudantes foi possível constatar que, do total de entrevistados, $60 \%$ eram do sexo masculino e $40 \%$ do sexo feminino, e a faixa etária era de no mínimo 19 anos e 26 anos, no máximo. Na avaliação referente à situação social e à aptidão do total de alunos, $60 \%$ são filhos de agricultores; $66,67 \%$ dos alunos possuem cultivo agrícola em suas residências; 66,67\% dos alunos moram na zona rural; 53,33\% dos alunos têm experiência em implantação de horta (Gráfico 1).

Gráfico 1 - Questionário aplicado na educação superior do IFRN, campus Ipanguaçu - Perfil dos estudantes

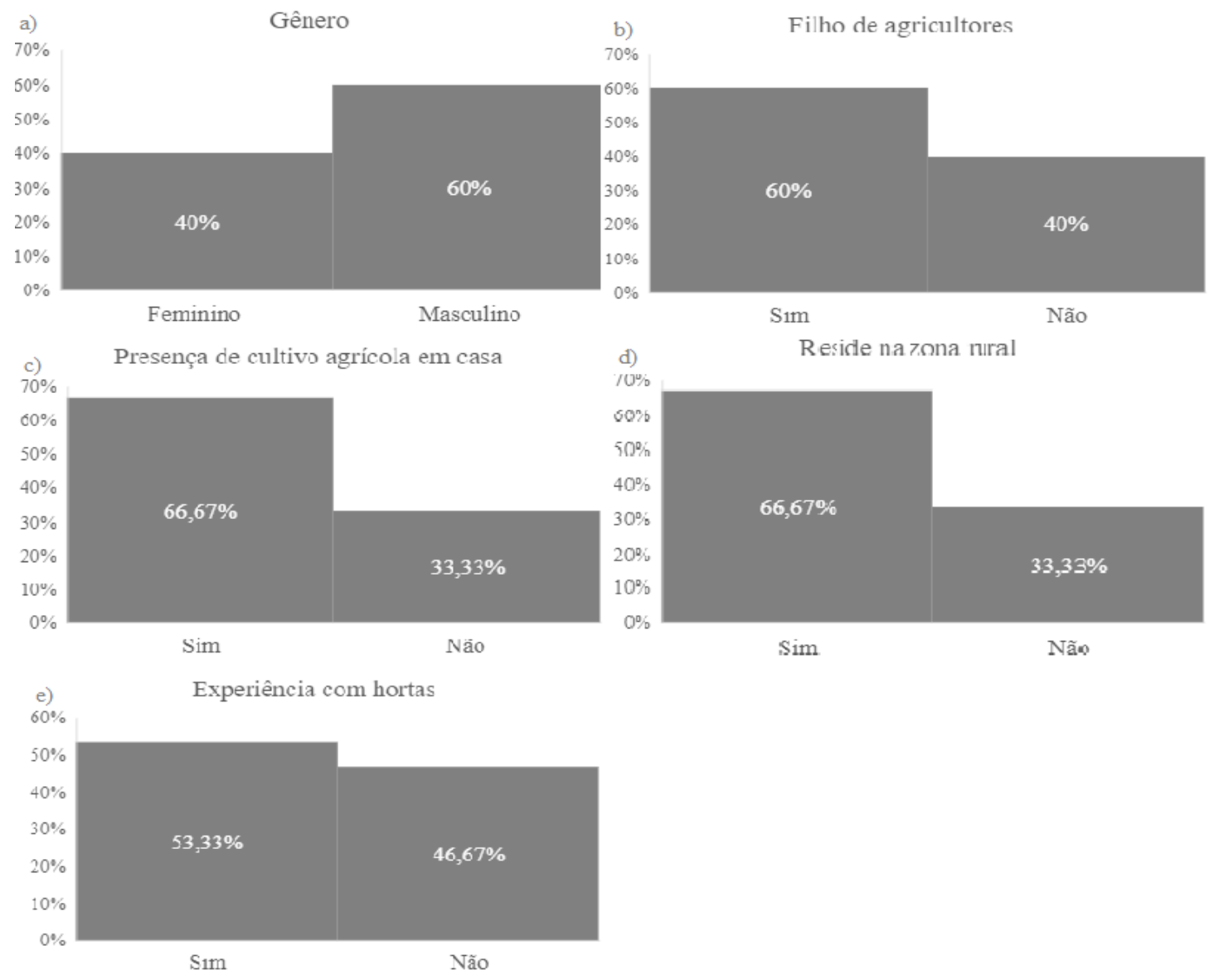

Fonte: Os autores (2021). 
Quando questionados se achavam que a horta auxiliou no processo de aprendizado, $100 \%$ responderam que sim; $100 \%$ dos entrevistados afirmaram que não houve dificuldade de trabalhar em grupo; e quando os alunos foram questionados se quando profissionais teriam segurança em recomendar a implantação e condução de uma horta a um produtor rural, todos responderam que sim (Gráfico 2).

Gráfico 2 - Questionário aplicado na educação superior do IFRN, campus Ipanguaçu Influência da horta na formação profissional dos estudantes
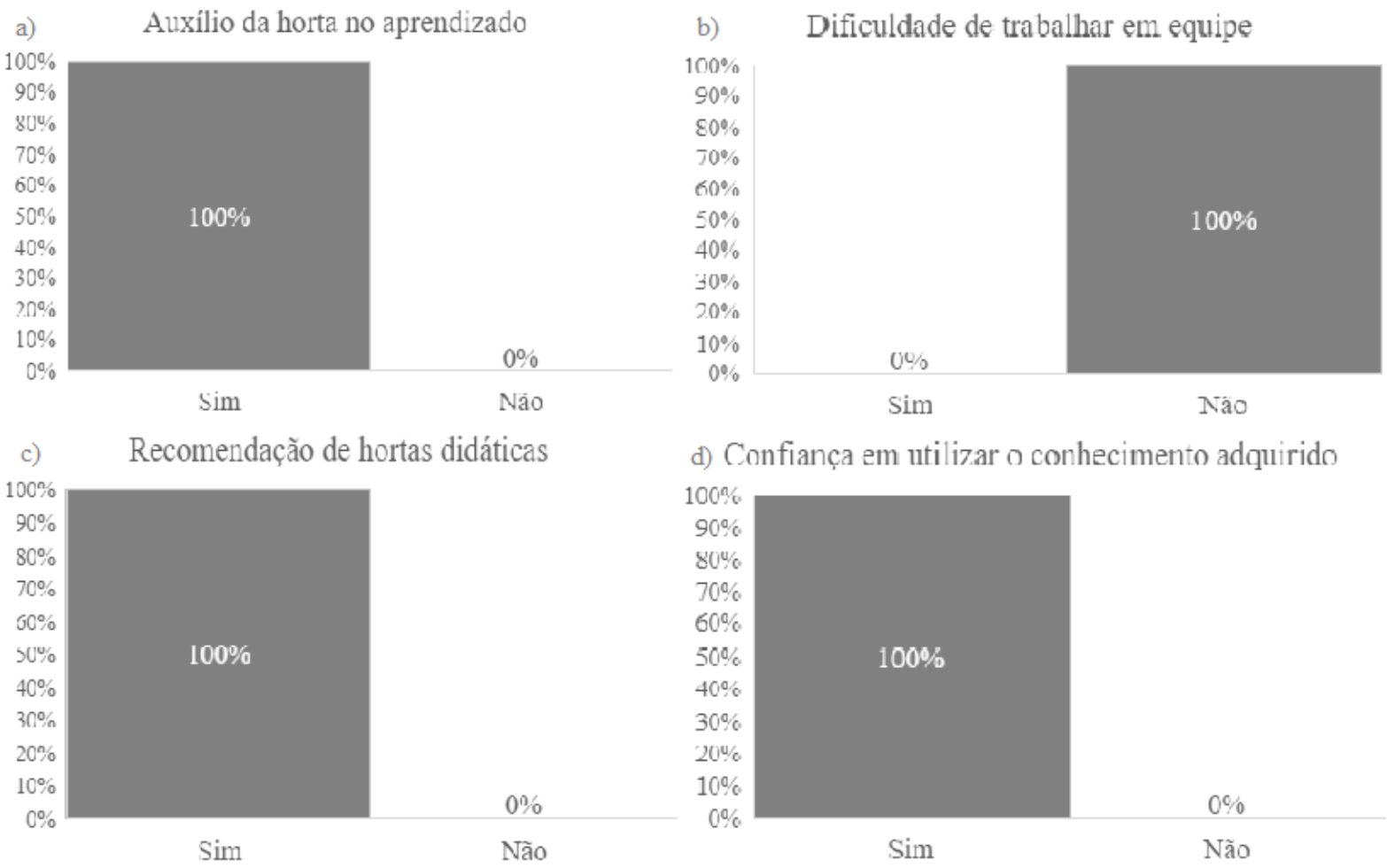

Fonte: Os autores (2021).

Resultado do questionário aplicado na educação básica - Escola Municipal Vereador João Medeiros Lopes - Itajá-RN

$\mathrm{Na}$ avaliação do perfil dos estudantes foi possível constatar que, do total de entrevistados, $80 \%$ eram do sexo feminino e $20 \%$ eram do sexo masculino, e a faixa etária era de 4 a 5 anos; $100 \%$ não cultivam hortaliças em suas residências, sendo que $60 \%$ deles tiveram esse contato apenas na escola; $100 \%$ dos estudantes aprovaram a horta na escola; e $80 \%$ dos entrevistados têm conhecimento sobre a existência de horta em outras instituições de ensino (Gráfico 3). 
Gráfico 3 - Questionário aplicado na educação básica - Escola Municipal Vereador João Medeiros Lopes, Itajá-RN - Perfil dos estudantes

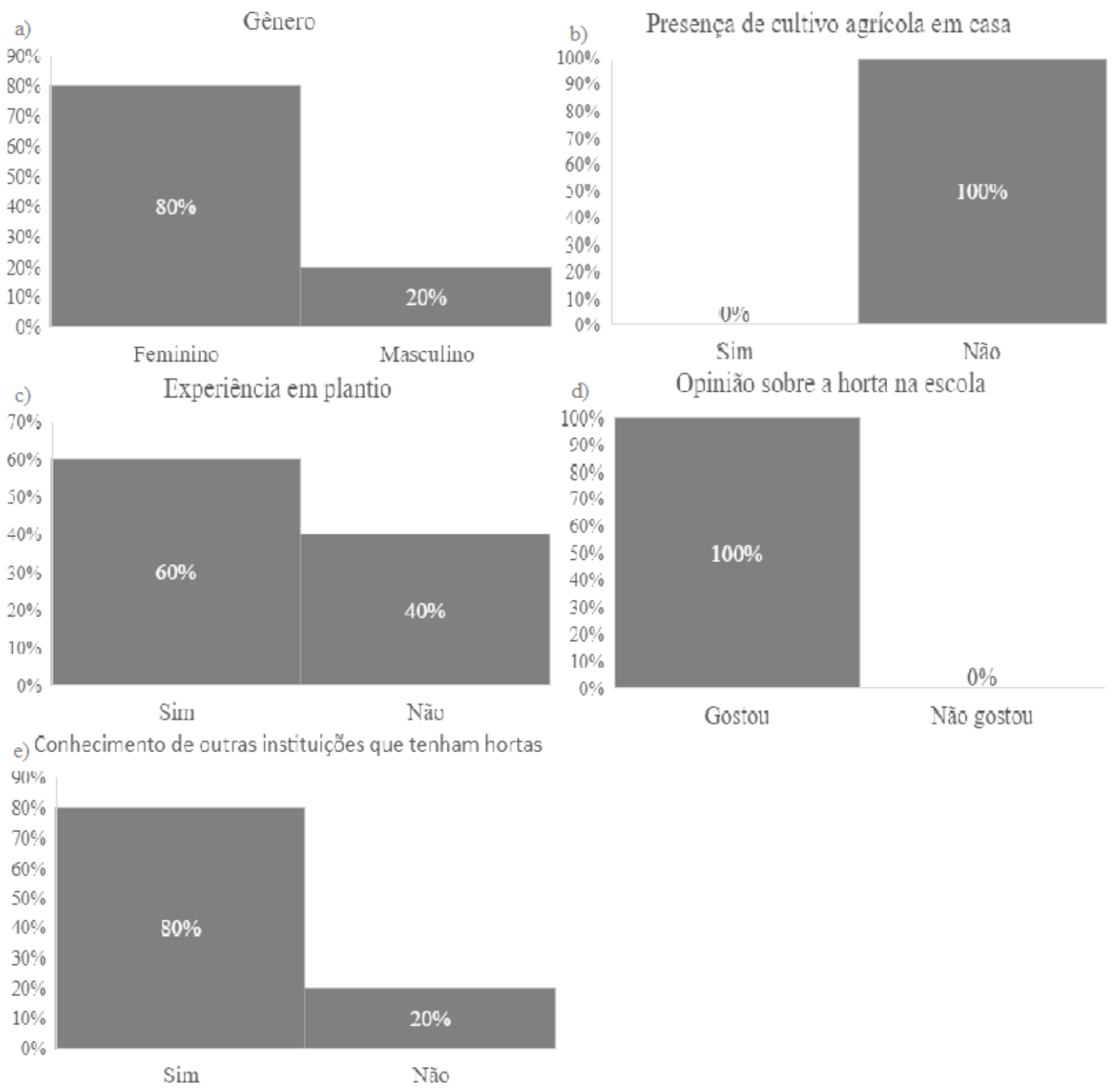

Fonte: Os autores (2021).

No que diz respeito às preferências dos estudantes com relação às hortaliças na escola: $30 \%$ preferem alface, $30 \%$ cenoura, $20 \%$ feijão e $20 \%$ tomate. Já em relação à preferência alimentar: $40 \%$ preferem cenoura, $30 \%$ tomate, $10 \%$ alface, $10 \%$ cebola e os outros $10 \%$ não têm preferência por nenhuma hortaliça (Gráfico 4). 
Gráfico 4 - Questionário aplicado na educação básica - Escola Municipal Vereador João Medeiros Lopes, Itajá-RN - Preferências dos estudantes
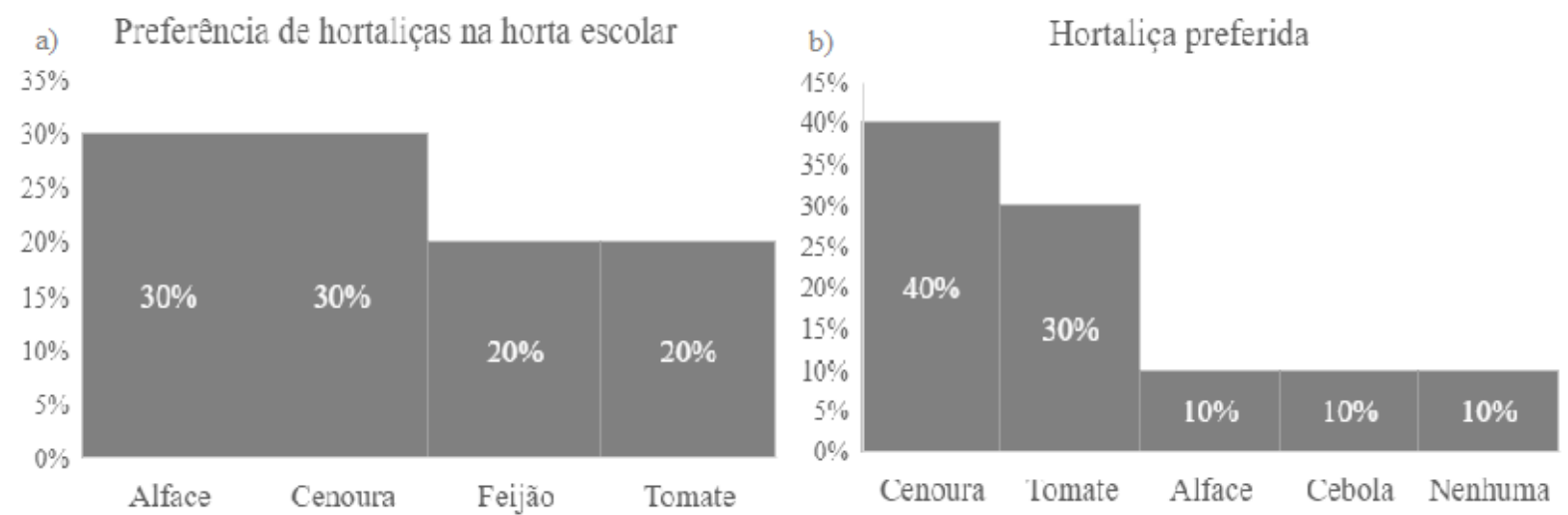

Fonte: Os autores (2021).

\section{Análise das perguntas do questionário aplicado na educação superior - Curso de Agroecologia do IFRN, campus Ipanguaçu}

Segundo pesquisas do Instituto Nacional de Estudos e Pesquisas Educacionais Anísio Teixeira (INEP), no ambiente escolar, mulheres são maioria. Outros dados do Censo da Educação Superior, referentes a 2017, também mostram a predominância das mulheres na educação superior, sendo elas 55\% dos estudantes ingressantes, $57 \%$ dos matriculados e $61 \%$ dos concluintes dos cursos de graduação. Na licenciatura, por exemplo, 70,6\% das matrículas são do sexo feminino, porém, os resultados encontrados aqui são divergentes e mesmo a educação sendo uma das principais lutas femininas no último século, os estudantes avaliados nessa pesquisa são, ainda, majoritariamente do sexo masculino, talvez por essa pesquisa se tratar de uma realidade mais rural, enquanto, geralmente, as demais pesquisas são feitas no contexto urbano.

Em relação à idade, foi possível observar que não existe um padrão comum. O que de fato observou-se foi a entrada no ensino superior após os 19 anos. Segundo a Lei nº 9.394 de 1996, que trata sobre as Diretrizes e Bases da Educação Nacional, a faixa etária dos estudantes que encerraram o ensino médio deverá ser 17 anos. Com essa informação é possível compreender que os estudantes entrevistados tiveram algum entrave ao adentrar no ensino superior na faixa etária correta, tendo em vista a amplitude na diferença de idade dos estudantes entrevistados. 
Foi possível analisar as intenções dos universitários nessa etapa do curso ( $5^{\circ}$ período), ressaltando o interesse de atuarem nesse campo de trabalho, além de receberem influência do meio rural que a maioria deles vive, e sua maior aproximação com o meio ambiente, abrangendo o contínuo convívio com os recursos naturais.

O cultivo agrícola com outros objetivos, que não sejam comerciais, mas uma prática pessoal, holística, terapêutica vem aumentando devido à consciência das pessoas. Considerando o resultado dessa pesquisa, ficou claro que não somente os filhos dos agricultores têm a experiência domiciliar com o cultivo agrícola, mas também os outros estudantes. Esse fato pode ser associado à ampliação da consciência de que os produtos naturais encontrados nas prateleiras dos supermercados são provenientes do uso de defensivos químicos, e que para se produzir esses alimentos não é necessário se ter uma grande área, ou seja, também é possível produzir hortaliças, frutas, legumes e verduras de qualidade em casa como forma de soberania alimentar e econômica.

De acordo com a FAO (2019), estima-se que até 2050 a população mundial alcance 9,8 bilhões de pessoas, e que cerca de $70 \%$ delas habitarão em áreas urbanas. Essa transformação espacial vem ocorrendo tanto pelo êxodo rural provocado pela industrialização quanto pela modernização tecnológica e conservadora que chegou aos campos a partir, principalmente, da década de 1960, alterando significativamente a distribuição da população no território brasileiro (NASCIMENTO et al., 2017).

A eficiência e a segurança do aprendizado são fatores primordiais como pilares desse trabalho no que se refere ao ensino profissional no ramo da horticultura e olericultura com a utilização das metodologias ativas utilizadas na implantação de hortas didáticas. Além do aprendizado prático, Oliveira (2018) afirmou que o manejo da horta permite que os alunos desenvolvam o senso de solidariedade a partir do convívio e do trabalho em equipe, em que uma precisa da outra nos momentos de ajuda; enquanto uma realiza uma atividade, como a capina, a outra faz o trabalho de desbaste e outra colhe.

O processo de aprendizagem por meio de práticas pedagógicas ativas é mais satisfatório. Através dessa metodologia, os alunos foram os protagonistas da disciplina, além de contribuir diretamente com o objetivo geral do curso, que é formar profissionais capazes de atuar de forma crítica e criativa na identificação e resolução de problemas, considerando seus aspectos tecnológicos, políticos, econômicos, sociais, ambientais, gerenciais, organizativos e culturais, com visão ética e humanística, em atendimento às demandas da sociedade, para as atividades do curso resultarem de um processo integrado de ensino, pesquisa e extensão de qualidade, capaz de conceder aos discentes discernimento e 
habilidades para pesquisa, conduzir tecnicamente mudanças, bem como utilizar racionalmente os recursos disponíveis e promover o equilíbrio ambiental (IFRN, 2012).

É válido citar que alguns projetos executados durante a disciplina foram apresentados em eventos científicos, sendo inclusive alguns premiados nesses eventos.

\section{Análise das perguntas do questionário aplicado na educação básica - Escola Municipal Vereador João Medeiros Lopes - Itajá-RN}

Essas crianças são atendidas pelo Plano Nacional da Educação (PNE) (2011-2020), que trata a Educação Infantil como prioridade e determina que a Educação Infantil seja um direito da criança de 0 a 5 anos, uma vez que, a partir dos 6 anos de idade, o ingresso delas é obrigatório no primeiro ano do ensino fundamental, que passa a ter duração de nove anos (BRASIL, 2014).

O cenário urbano, apesar de distinto do rural, pode combinar muito com canteiros repletos de pés de alface, cenoura, entre outros vegetais, porém, esses dois cenários tão diferentes têm começado um tipo de coexistência muito interessante e que pode se refletir diretamente na qualidade do ar dos grandes centros urbanos (O’REILLY, 2014).

A ausência de cultivos agrícolas nas residências das crianças pode ser explicada pela facilidade que temos hoje de poder comprar esses alimentos que antes eram cultivados por um maior número de pessoas e atualmente são facilmente encontrados nas prateleiras de quitandas e supermercados.

As atividades realizadas na horta promovem um momento de mais contato com o solo, insetos e pequenos animais que visitam aquele ambiente, visto que crianças do meio urbano estão cada vez mais afastadas do contato com a natureza. Tais atividades auxiliam no desenvolvimento da consciência de que é necessário ser adotado um estilo de vida menos nocivo ao meio ambiente, bem como a integração das crianças com os problemas ambientais, principalmente, com o uso de defensivos agrícolas vivenciado a partir do universo da horta escolar (CRIBB, 2010).

A horta na escola é de suma importância, pois ela está definida a partir do momento em que podemos reproduzir os fenômenos da natureza e as transformações produzidas pelo homem. Além disso, ela reforça e contribui no enriquecimento da merenda escolar; sua introdução faz com que os docentes trabalhem de forma didática, levando os discentes a interagirem em grupos, para serem mais observadores e questionadores, através de sua existência no ambiente escolar (ARAÚJO et al., 2017). 
Para Eno et al. (2016), as atividades realizadas na horta escolar contribuem para que os alunos desenvolvam uma compreensão da necessidade da preservação do meio ambiente escolar, estimulam a capacidade do trabalho em equipe e da cooperação e ainda proporcionam um maior contato com a natureza. Também é nesse espaço público que se pode valorizar a construção da formação de valores e atitudes positivas, entre outras possibilidades que impactarão permanentemente a vida.

Além disso, a horta escolar contribui diretamente para a saúde dos alunos, uma vez que garante alimentos frescos, essenciais para uma boa qualidade de vida (MAURICIO, 2020).

\section{Considerações finais}

Para os futuros tecnólogos em agroecologia e para as crianças da educação infantil, a implantação das hortas foi efetiva e trouxe efeitos positivos nos dois níveis da educação, educação básica e educação superior, apesar de serem bastante distintos. Para os graduandos, foram proporcionadas experiências que serão futuramente usadas na carreira profissional, na assistência e na extensão rural com os agricultores e agricultoras familiares. Já para as crianças do ensino básico, a implantação da horta foi eficiente na sensibilização para a educação ambiental, quanto à produção de alimento sem uso de insumos químicos, visando um maior cuidado com o solo, uso racional de água e com os demais seres vivos que partilham e convivem naquele ambiente. Portanto, a implantação de hortas é uma metodologia ativa de ensino, que pode ser usada em diferentes níveis de ensino e com diferentes fins.

\section{Referências}

ARAÚJO, A. et al. Projeto de horta orgânica para uma unidade escolar da rede pública de ensino do município do Rio de Janeiro, RJ. Revista Presença, Rio de Janeiro, v. 3, n. 8, p. 25-36, jul. 2017. Disponível em: https://revistapresenca.celsolisboa.edu.br/index.php/numerohum/article/view/106. Acesso em: 25 ago. 2021.

BRASIL. Lei no 13.005, de 25 de junho de 2014. Aprova o Plano Nacional de Educação PNE e dá outras providências. Brasília, DF, 2014. Disponível em: http://www.planalto.gov.br/ccivil_03/_Ato2011-2014/2014/Lei/L13005.htm. Acesso em: 30 set. 2019.

CRIBB, S. L. S. P. Contribuições da educação ambiental e horta escolar na promoção de melhorias ao ensino, à saúde e ao ambiente. Ensino, Saúde e Ambiente, Niterói, v. 3, n. 1, p. 
42-60, abr. 2010. Doi: 10.22409/resa2010.v3i1.a21103. Disponível em:

https://periodicos.uff.br/ensinosaudeambiente/article/view/21103. Acesso em: 30 maio 2019.

CYPRIANO, R. J. et al. Horta escolar: um laboratório vivo. Educação Ambiental em Ação, Novo Hamburgo, v. 20, n. 42, set. 2018. Disponível

em: http://www.revistaea.org/artigo.php?idartigo=1400. Acesso em: 10 ago. 2021.

ENO, É. G. J.; LUNA, R. R.; LIMA, R. A. Horta na escola: incentivo ao cultivo e a interação com o meio ambiente. Revista Eletrônica em Gestão, Educação e Tecnologia Ambiental, Santa Maria, v. 19, n. 1, p. 248-253, jan. 2016. Doi: 10.5902/22361170. Disponível em: https://redib.org/Record/oai_articulo1039339-horta-na-escola-incentivo-ao-cultivo-e-aintera\%C3\%A7\%C3\%A3o-com-o-meio-ambiente. Acesso em: 30 maio 2021.

LEITE, A. L. C. C. Hortas na escola como ferramenta de ensino na educação ambiental: uma análise bibliométrica. 2020. 40 f. Trabalho de Conclusão de Curso (Especialização em práticas Educacionais em Ciências e pluralidade) - Universidade Tecnológica Federal do Paraná, Dois Vizinhos-PR, 2020. Disponível em:

http://repositorio.utfpr.edu.br:8080/jspui/handle/1/25225. Acesso em: 30 mar. 2019.

LIZ, R. S. Etapas para o planejamento e implantação de horta urbana. Comunicado Técnico, Brasília, v. 9, n. 1, p. 1-12, dez. 2016. Disponível em:

https://www.infoteca.cnptia.embrapa.br/bitstream/doc/780884/1/cot39.pdf. Acesso em: 30 mar. 2019

MARTINELLI, S. S.; CAVALLI, S. B. Alimentação saudável e sustentável: uma revisão narrativa sobre desafios e perspectivas. Ciência \& Saúde Coletiva, Rio de Janeiro, v. 24, n. 11, nov. 2019. Doi: 10.1590/1413-812320182411.30572017. Disponível em: https://www.scielo.br/j/csc/a/z76hs5QXmyTVZDdBDJXHTwz/?lang=pt. Acesso em: 30 maio 2019.

MAURICIO, C. C. Desenvolvimento Sustentável - Estudo de caso: projeto modelo de horta urbana comunitária em uma superquadra do Distrito Federal utilizando a biofilia. 2020. 66 f. Relatório Final de Pesquisa (Iniciação científica) - Faculdade de Tecnologia e Ciências Sociais Aplicadas, Centro Universitário de Brasília, Brasília, 2020. Disponível em: https://www.publicacoesacademicas.uniceub.br/pic/article/view/7487. Acesso em: 25 ago. 2021.

NASCIMENTO, C. A. S. et al. A migração do campo para os centros urbanos no Brasil: da desterritorialização no meio rural ao caos nas grandes cidades. In: CONGRESSO INTERNACIONAL FOMERCO - INTEGRAÇÃO REGIONAL EM TEMPOS DE CRISE: DESAFIOS POLÍTICOS E DILEMAS TEÓRICOS, 16., 2017, Salvador. Anais [...].

Salvador: UFBA, 2017. Disponível em:

http://www.congresso2017.fomerco.com.br/resources/anais/8/1502235198_ARQUIVO_fome rco_AMIGRACAODOCAMPOPARAOSCENTROSURBANOSNOBRASIL.pdf. Acesso em: 9 set. 2019.

OLIVEIRA, J. A. C. A relevância e os usos da horta no ensino de ciências nas escolas do Campo de Torres-RS. 2018. 44 f. Trabalho de Conclusão de Curso (Graduação em Educação do Campo) - Universidade Federal do Rio Grande do Sul, Campus Litoral Norte, 
Tramandaí, 2018. Disponível em: http://hdl.handle.net/10183/181658. Acesso em: 1 jun. 2019.

ONU NEWS. ONU prevê que cidades abriguem 70\% da população mundial até 2050. Nações Unidas, 19 de fevereiro de 2019. Disponível em:

https://news.un.org/pt/story/2019/02/1660701. Acesso em: 25 ago. 2021.

O’REILLY, É. M. Agricultura urbana: um estudo de caso do Projeto Hortas Cariocas em Manguinhos, Rio de Janeiro. 2014. 87 f. Trabalho de Conclusão de Curso (Graduação em Engenharia Ambiental) - Universidade Federal do Rio de Janeiro, Rio de Janeiro, 2014. Disponível em: http://repositorio.poli.ufrj.br/monografias/monopoli10009377.pdf. Acesso em: 21 ago. 2021.

SILVA, R. S.; SCALABRIN, R. Relato de experiência do PIBID da escola municipal de ensino fundamental Juan Pablo: horta educativa com base na interdisciplinaridade. Pesquisas e Práticas Educativas, Ilha Solteira, v. 1, p. 1-16, 2020. Doi: 10.47321/PePE.26755149.2020.1.e202021. Disponível em:

https://epf.unesp.br/pepe/index.php/pepe/article/view/40. Acesso em: 21 ago. 2021.

SIMONETTI, E. R. S.; LOPES, S. R.; OLIVEIRA, A. C. S. Relato de experiência: projeto de extensão agricultura urbana, hortas orgânicas com materiais recicláveis em pequenos espaços. Revista Craibeiras de Agroecologia, Rio Largo, v. 1, n. 1, 2017. Disponível em: https://www.seer.ufal.br/index.php/era/article/view/3656. Acesso em: 21 ago. 2021.

Submetido em 17 de maio de 2021.

Aprovado em 25 de julho de 2021. 